\title{
Studi Sistem Pencahayaan Buatan Adaptif untuk Selasar Aktivitas Gedung Baru Departemen Desain Interior ITS
}

\author{
Caesario Ari Budianto ${ }^{1}$, R. Adi Wardoyo², Thomas Ari Kristianto ${ }^{3}$, Anggra Ayu \\ Rucitra4, Okta Putra Setio Ardianto ${ }^{5}$ \\ 1,2,3,4,5 Departemen Desain Interior, Fakultas Arsitektur, Desain dan Perencanaan, Institut Teknologi Sepuluh \\ Nopember, Surabaya 60111 Indonesia \\ 1caesario.budianto@interior.its.ac.id, ²wardoyoadi@interior.com, ${ }^{3}$ thomasjawa@prodes.its.ac.id, \\ 4anggra@interior.its.ac.id, ${ }^{5}$ oktaputra07@gmail.com
}

\begin{abstract}
ABSTRAK
Pada umumnya, selasar memiliki fungsi tunggal sebagai jalur sirkulasi. Dalam pembangunan gedung baru Departemen Desain Interior ITS, inovasi diberikan dengan menghadirkan konsep multifungsi yang disebut selasar aktivitas. Konsep multifungsi ini menambahkan fasilitas area diskusi asistensi dan galeri karya pada area selasar yang bertujuan mewadahi kebutuhan aktivitas mahasiswa. Untuk menunjang konsep tersebut, faktor yang harus diperhatikan adalah pencahayaan, baik sebagai penerangan umum maupun sebagai elemen pendukung agar kebutuhan mahasiswa dapat terpenuhi dengan baik.

Metode penelitian yang digunakan adalah metode deskriptif yang menggambarkan hubungan antara objek penelitian dengan sistem pencahayaan buatan, dengan teknik eksperimental berupa simulasi menggunakan software DIALux. Data yang dikumpulkan meliputi dokumen perencanaan gedung baru Departemen Desain Interior ITS dan standar perancangan pencahayaan bangunan. Hasil dari studi ini yaitu perlunya penambahan lampu pada area selasar berupa accent lighting dan task lighting dengan ukuran lux tertentu untuk menunjang kebutuhan mahasiswa sewaktu-waktu. Temuan dari studi ini diharapkan dapat menjadi rekomendasi perencanaan tata pencahayaan di selasar gedung baru Departemen Desain Interior ITS.
\end{abstract}

Kata kunci: selasar aktivitas; kebutuhan mahasiswa; pencahayaan buatan

\section{ABSTRACT}

Generaly, lobby has a single function as a circulation path. In the construction of a new building for the ITS Interior Design Department, innovation is provided by presenting a multifunctional concept called activity lobby. This multifunctional concept adds facilities for the discussion area of assistance and a gallery of works in the lobby area that aims to accommodate the needs of student activities. To support this concept, the factor that must be considered is lighting, both as general lighting and as a supporting element so that student needs can be met properly.

The research method used is descriptive method that describes the relationship between research objects with artificial lighting systems, with experimental techniques in the form of simulations using DIALux software. Data collected includes new building planning documents of the ITS Interior Design Department and building lighting design standards. The results of this study are the need for additional lights in the lobby area in the form of accent lighting and task lighting with certain lux sizes to support student needs at any time. The findings of this study are expected to be a recommendation for lighting planning in the lobby of the new building of the ITS Interior Design Department.

Keyword: activity lobby; student needs; artificial lighting

\section{PENDAHULUAN}

Selasar secara umum memiliki fungsi sebagai jalur sirkulasi yang menghubungkan satu area dengan area lain. Di Departemen Desain Interior ITS, mahasiswa memiliki kebiasaan untuk melakukan kegiatan belajar mengajar di area selasar. Oleh karena itu, pada perencanaan 
gedung baru Departemen Desain Interior ITS, inovasi akan dihadirkan melalui penambahan konsep multifungsi pada area selasar, dengan fasilitas area diskusi dan pameran karya.

Untuk membangun konsep multifungsi atau multi aktivitas pada selasar, diperlukan beberapa faktor penunjang, antara lain pencahayaan. Pencahayaan yang diperlukan tidak hanya pencahayaan alami, tetapi juga pencahayaan buatan karena kegiatan mahasiswa di area selasar dapat dilakukan sewaktu-waktu. Pencahayaan buatan yang digunakan pun tidak hanya pencahayaan umum tetapi juga pencahayaan khusus yang ditempatkan di masing-masing area kerja mahasiswa agar setiap kegiatan dapat berjalan secara optimal.

Berdasarkan latar belakang tersebut diperlukan sebuah studi pencahayaan buatan untuk mengetehui titik pencahayaan buatan untuk mengetahui titik pencahayaan yang efektif untuk diaplikasikan pada area selasar gedung baru Departemen Desain Interior ITS.

\section{METODE PENELITIAN}

Bagan 1. Proses Tahap Penelitian

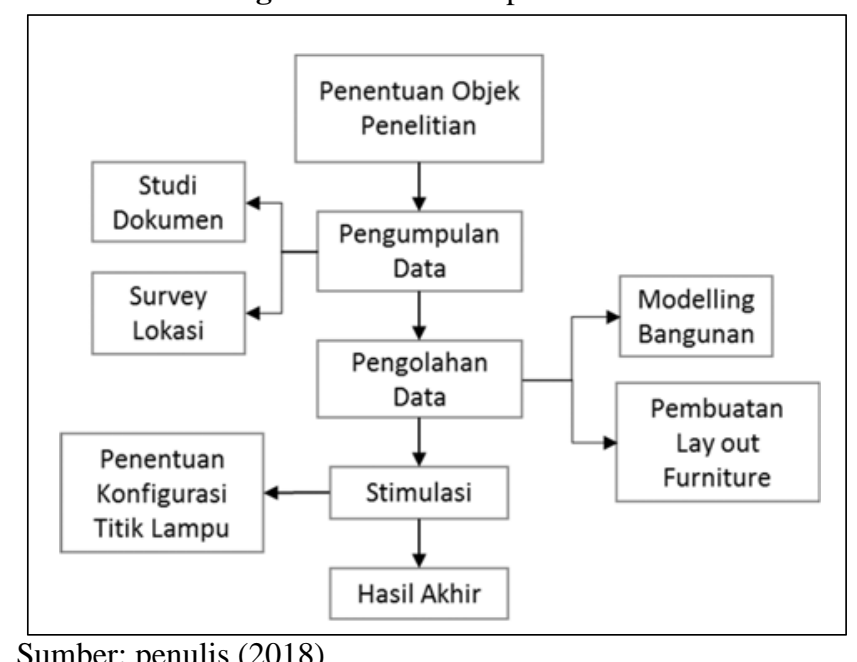

Sumber: penulis (2018)

Penelitian menggunakan variabel bebas berupa pencahayaan adaptif, dan variabel terikat yaitu aktivitas pengguna selasar gedung baru Departemen Desain Interior ITS. Metode penelitian yang digunakan yaitu eksperimental kuantitatif dengan pembahasan yang menggunakan metode secara deskriptif. Eksperimen yang dilakukan berupa simulasi untuk mengetahui kondisi ruang dengan kondisi pencahayaan alami dan buatan pada tanggal 21 Maret, 22 Juni dan 22 Desember pada pukul 08.00, 12.00 dan 18.00. Penentuan waktu berdasarkan pergerakan dan posisi matahari terhadap bumi setiap tahunnya di daerah selasar, serta waktu penggunaan selasar untuk aktivitas mahasiswa dengan intensitas paling tinggi setiap harinya.

\section{A. Pengumpulan Data}

Pada tahap pengumpulan data, informasi didapat melalui studi dokumenter dan survey lokasi. Melalui studi dokumenter, dokumen yang digunakan antara lain dokumen perencanaan gedung, literatur mengenai pencahayaan dan standar perancangan pencahayaan bangunan khususnya di area selasar.

Sedangkan pengumpulan data utama didapatkan melalui survey lokasi. Objek yang digunakan dalam penelitian ini, merupakan gedung baru Departemen Desain Interior ITS, berada di Timur kota Surabaya dengan koordinat $-7.30^{\circ}$ BT $112.70^{\circ}$ LS. Posisi bangunan berada 
di jalan Despro berdampingan dengan gedung workshop desain interior dan menghadap ke arah barat dengan tiga entrance yaitu dua di sisi barat dan satu di sisi timur.

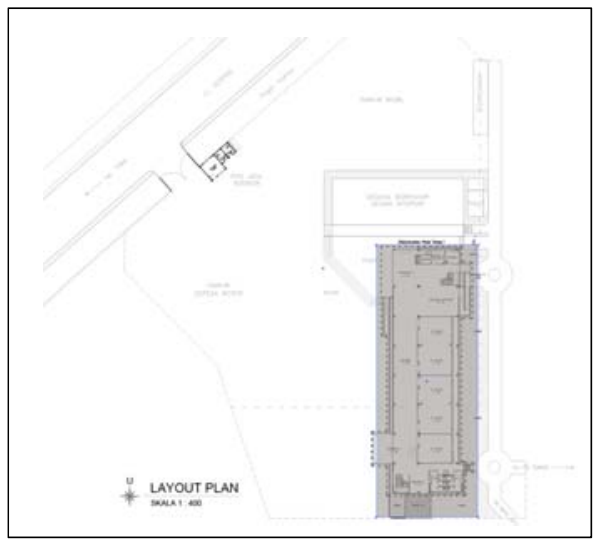

Gambar 1. Layout Plan Gedung baru Departemen Desain Interior ITS (gambar yang diarsir)

Sumber: penulis (2018)

\section{B. Pengolahan Data}

Tahap pengolahan data dilakukan dengan pembuatan modelling bangunan berdasarkan dokumen rencana pembangunan gedung dan penyusunan layout furniture area selasar lantai 1 dan area selasar lantai 3. Penentuan objek didasarkan pada pertimbangan frekuensi aktifitas mahasiswa terbanyak dari keseluruhan bangunan gedung. Layout furniture dibuat berdasarkan kebutuhan mahasiswa di area selasar untuk menentukan pencahayaan yang paling efektif untuk digunakan.

Area Selasar Lantai Satu

Tabel 1. Pembagian Layout Furniture dan Titik Pencahayaan Buatan pada Area Selasar Lantai 1

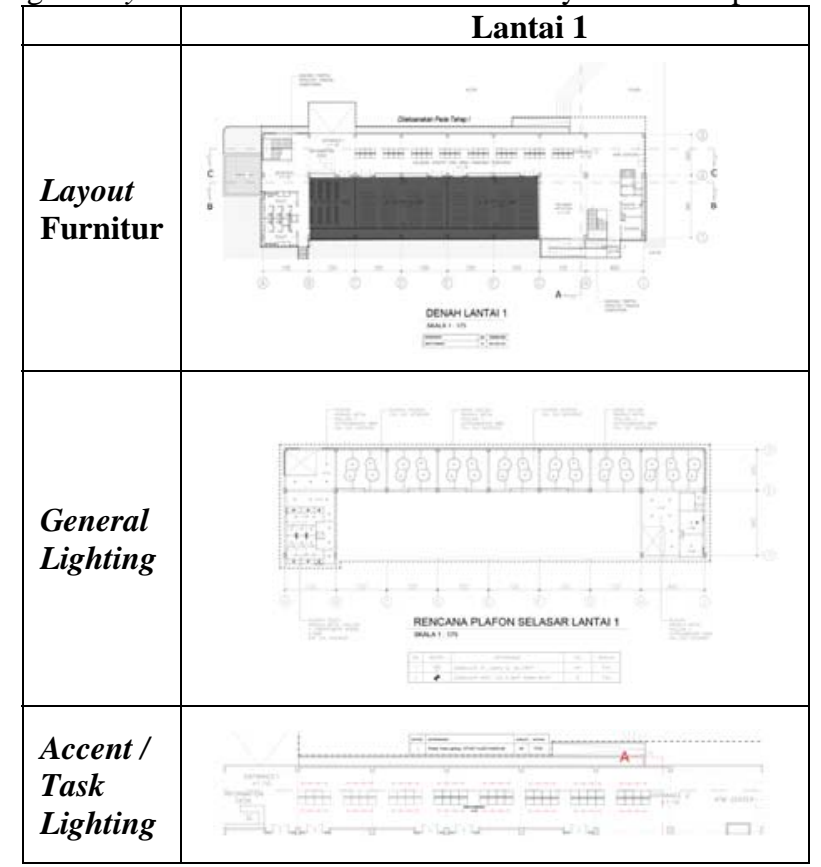

Sumber: Penulis (2018) 
Caesario A. Budianto, R. Adi Wardoyo, Thomas A. Kristianto, Anggra A. Rucitra, Okta P. S. Ardianto Studi Sistem Pencahayaan Buatan Adaptif untuk Selasar Aktivitas Gedung Baru Departemen Desain Interior ITS

Area lantai satu meliputi beberapa rencana pembagian ruang yaitu selasar, dua ruang studio dengan masing-masing berkapasitas 80 orang, satu kelas berkapasitas 40 orang, mushola, toilet, ATM Center, gudang, janitor dan pantry. Area selasar juga terbagi dalam 2 area, yaitu area pameran karya dan kegiatan belajar mengajar.

Untuk memfasilitasi kegiatan pameran, pada selasar, terdapat meja display berukuran 80x60x80 cm untuk memajang karya 3 dimensi dan sketsel berukuran 80x10x210 untuk memajang karya 2 dimensi. Area pamer berpola linear agar pengunjung dapat menikmati pameran secara runtut, dengan jalur sirkulasi selebar $120 \mathrm{~cm}$ yang terdapat di setiap 4 baris meja display. Pameran bersifat temporer sehingga penataan furnitur bersifat semi-aktif, agar dapat diubah sewaktu-waktu.

Ketika pameran sedang tidak diadakan, area selasar dapat digunakan sebagai kegiatan belajar mengajar. Area ini dibiarkan tanpa furnitur untuk memfasilitasi beberapa mata kuliah yang memerlukan tempat untuk meletakkan material desain dengan dimensi yang cukup besar atau aktivitas yang harus dilakukan di luar ruangan.

\section{Area Selasar Lantai Tiga}

Tabel 2. Pembagian Layout Furniture dan Titik Pencahayaan Buatan pada Area Selasar Lantai 3

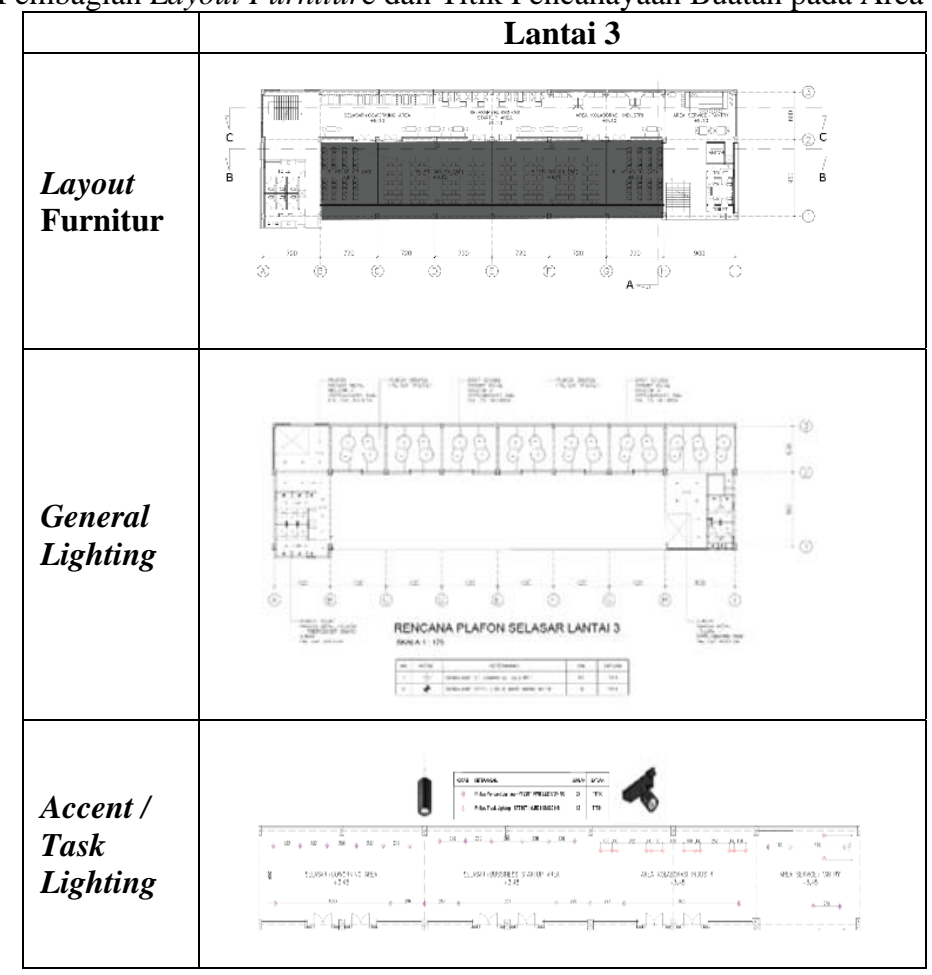

Sumber: Penulis (2018)

Pada lantai tiga, rencana pembagian ruang sama seperti pada lantai satu, yang terdiri atas selasar, ruang studio, ruang kelas, toilet dan pantry. Untuk area selasar, area dibedakan cukup beragam karena difungsikan untuk kegiatan diskusi (co-working), business startup, kolaborasi industri dan self-service.

Area co-working digunakan sebagai tempat berdiskusi dan mengerjakan tugas, letaknya tersebar di sepanjang area selasar. Area ini dibedakan menjadi 2 jenis, yaitu area publik dan area privat. Untuk area privat, diberi furnitur berupa 1 meja kerja berukuran 120x76x75 cm dan 
2 kursi kerja berukuran 120x40x50 cm. Meja dan kursi ditata secara berkelompok sebanyak 6 dan diberi pembatas berupa bilik untuk menjaga ketenangan pengguna. Untuk area publik, diberi furnitur berupa meja kerja berukuran sama, sofa berukuran 100x175x50 cm dan stool berukuran 50x50x50 cm. Meja dan kursi juga ditata secara berkelompok sebanyak 8 buah dan tersebar di depan ruang studio.

Area business startup digunakan sebagai tempat berkumpul komunitas bisnis dengan aktivitas memajang karya bisnis dan pertemuan singkat. Untuk memfasilitasi kegiatan ini, diberi furnitur berupa meja kerja dan 4 kursi kerja, lemari pajang produk dan dibatasi oleh satu partisi. Area kolaborasi industri merupakan area pamer, namun lebih dikhususkan untuk memajang produk industri yang bekerja sama dengan pihak Departemen. Untuk itu, furnitur yang digunakan berupa meja display berukuran 80x60x80 cm dan sketsel berukuran 60x118 $\mathrm{cm}$. Area self-service digunakan untuk memenuhi kebutuhan mahasiswa untuk mencetak dokumen dan bersifat mandiri. Area ini bergabung dengan area pantry. Untuk memfasilitasi kegiatan, diberi furnitur berupa mesin fotokopi, mesin cetak dan komputer, dapur, kulkas dan area makan.

\section{Simulasi}

Tahap simulasi dilakukan untuk menguji konfigurasi pencahayaan yang telah dibuat dengan menggunakan software DIALux. Pada selasar lantai satu dan tiga menggunakan general lighting yang sama masing-masing berjumlah 60 titik. Sedangkan pada lantai tiga menggunakan accent lighting dan task lighting masing-masing 12 titik dan 27 titik. Pada lantai satu accent lighting berjumlah 64 titik sesuai kapasitas display. Letak accent lighting yang berupa tracklight tersebut berjarak $60 \mathrm{~cm}$ dari as display untuk menghasilkan sudut pencahayaan $30^{\circ}$ terhadap bidang permukaan display.

Tabel 3. Jenis lighting yang digunakan pada penelitian

\begin{tabular}{|c|c|c|}
\hline $\begin{array}{c}\text { Area Selasar / Jenis } \\
\text { Lampu }\end{array}$ & Lantai 1 & Lantai 3 \\
\hline General Lighting & \multicolumn{2}{|c|}{ 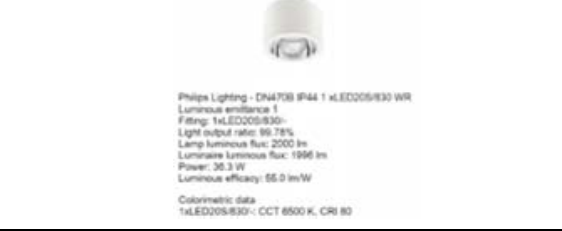 } \\
\hline Accent Lighting & 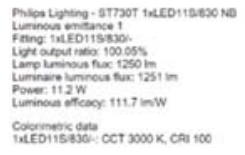 & 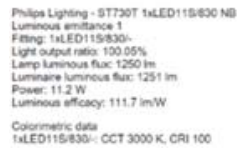 \\
\hline Task Lighting & - & 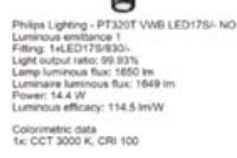 \\
\hline
\end{tabular}

Sumber: Penulis (2018) 
Caesario A. Budianto, R. Adi Wardoyo, Thomas A. Kristianto, Anggra A. Rucitra, Okta P. S. Ardianto

Studi Sistem Pencahayaan Buatan Adaptif untuk Selasar Aktivitas Gedung Baru Departemen Desain Interior ITS

\section{Analisa Data}

Tahap analisa data dilakukan dalam 3 tahap, yaitu analisa dokumentasi, hasil simulasi dan perbanding hasil simulasi dengan literatur. Analisa dokumentasi menghasilkan parameter yang digunakan untuk simulasi, analisa hasil simulasi menghasilkan jenis pencahayaan yang sesuai pada objek penelitian, dan analisa perbandingan hasil simulasi dan literatur menghasilkan rekomendasi jenis dan konfigurasi pencahayaan yang optimal untuk objek penelitian.

\section{HASIL PENELITIAN DAN PEMBAHASAN}

\section{A. Studi Teori Pendukung}

Pencahayaan buatan yaitu pencahayaan yang memiliki sumber dari barang-barang yang dibuat oleh manusia, yang warna dan efeknya dapat diatur sesuai yang diinginkan. Keunggulan dari pencahayaan buatan yaitu sumber cahaya tidak bergantung pada waktu dan cuaca, melainkan listrik atau bahan bakar. Pencahayaan buatan terdiri atas empat jenis, yaitu general lighting, accent lighting, task lighting dan decorative lighting. General lighting yaitu pencahayaan yang memiliki sumber cukup besar dan digunakan sebagai penerangan utama dalam ruang. Accent lighting yaitu pencahayaan yang digunakan untuk menerangi obyek khusus dan berfungsi menambah estetika ruang. Task lighting yaitu pencahayaan yang digunakan untuk mempermudah aktivitas yang dilakukan dalam ruang. Sedangkan decorative lighting yaitu pencahayaan yang digunakan khusus untuk membuat tampilan yang menarik dalam ruang. Pengaplikasian pencahayaan pada ruangan erat kaitannya dengan pemilihan jenis sumber cahaya. Pemilihan janis lampu sebagai sumber cahaya buatan berpengaruh dalam menciptakan suasana interior yang nyaman. Dalam memilih lampu, kriteria yang harus dipertimbangkan antara lain efisiensi sumber cahaya, umur lampu, indeks penghasil warna, dan warna cahaya. Lampu dengan efisiensi yang tinggi akan menggunakan lebih sedikit energi.

Silau dapat terjadi jika kecerahan dari suatu bagian interior jauh melebihi kecerahan dari interior tersebut pada umumnya. Sumber silau yang paling umum adalah kecerahan yang berlebihan dari armatur dan jendela, baik secara langsung maupun pantulan. Silau terbagi menjadi dua jenis, yaitu silau yang menyebabkan ketidakmampuan melihat (disability glare) dan silau yang menyebabkan ketidaknyamanan melihat (discomfort glare). Untuk meminimalisir silau yang dinilai dapat mengurangi keefektifan aktifitas dalam ruangan dibutuhkan sistem pencahayaan yang baik pada ruangan. Dalam pengaturan pencahayaan, terdapat beberapa sistem yang dapat diterapkan dan dibagi menjadi tiga jenis, yaitu sistem pencahayaan merata, setempat dan gabungan. Sistem pencahayaan merata memberikan tingkat pencahayaan merata dalam ruang, sedangkan sistem pencahayaan setempat hanya berfokus pada satu titik dengan intensitas lebih tinggi dibandingkan sekitarnya. Sistem pencahayaan gabungan memberikan tingkat pencahayaan yang merata dengan posisi dekat dengan obyek. Selain sistem pencahayaan, dalam pencahayaan buatan juga dikenal beberapa teknik pencahayaan antara lain pencahayaan langsung dan tidak langsung, pencahayaan ke bawah dan ke atas, serta pencahayaan dari belakang, depan dan samping.

Dalam perencanaan sistem pencahayaan buatan, terdapat rekomendasi tingkat pencahayaan minimum dan renderasi warna untuk berbagai fungsi ruang berdasarkan SNI 036575-2001, yaitu: 
Tabel 4. Rekomendasi Tingkat Pencahayaan Dalam Gedung

\begin{tabular}{|c|c|c|c|}
\hline & Macam Pekerjaan & Lux & Contoh \\
\hline \multirow{3}{*}{1} & \multirow{3}{*}{$\begin{array}{l}\text { Pencahayaan untuk daerah yang } \\
\text { tidak terus-menerus digunakan }\end{array}$} & 20 & Humanisasi minimum \\
\hline & & 50 & $\begin{array}{l}\text { Parkir dan daerah sirkulasi di } \\
\text { dalam ruangan }\end{array}$ \\
\hline & & 100 & Kamar tidur hotel \\
\hline \multirow{3}{*}{2} & \multirow{3}{*}{$\begin{array}{l}\text { Pencahayaan untuk bekerja di } \\
\text { dalam ruangan }\end{array}$} & 200 & $\begin{array}{l}\text { Membaca dan menulis yang } \\
\text { terus menerus }\end{array}$ \\
\hline & & 350 & $\begin{array}{l}\text { Pencahayaan umum untuk } \\
\text { perkantoran, pertokoan, } \\
\text { membaca, menulis }\end{array}$ \\
\hline & & 400 & Ruang gambar \\
\hline \multirow{3}{*}{3} & \multirow{3}{*}{$\begin{array}{l}\text { Pencahayaan setempat untuk } \\
\text { pekerjaan teliti }\end{array}$} & 750 & $\begin{array}{l}\text { Pembacaan untuk koreksi } \\
\text { tulisan }\end{array}$ \\
\hline & & 1000 & Gambar yang sangat teliti \\
\hline & & 2000 & $\begin{array}{l}\text { Pekerjaan secara rinci dan } \\
\text { presisi }\end{array}$ \\
\hline
\end{tabular}

Sumber: Hasil Kajian Lapangan (2018)

Terkait beberapa penjelasan tersebut, dalam pencahayaan buatan, distribusi luminansi digunakan sebagai pelengkap keberadaan tingkat pencahayaan di dalam ruangan. Hal yang harus diperhatikan yaitu rentang luminansi permukaan langit-langit dan dinding, distribusi laminansi bidang kerja, nilai maksimum luminansi armatur dan skala luminansi untuk pencahayaan interior.

Renderasi atau penghasil warna merupakan kemampuan sumber cahaya untuk mereproduksi warna sesungguhnya dari berbagai objek dibandingkan dengan sumber cahaya yang ideal. Nilai maksimum secara teoritis dari indeks renderasi warna adalah 100. Pembagian temperatur dan harga renderasi warna ditampilkan pada tabel berikut:

Tabel 5. Pembagian Temperatur dan Harga Renderasi Warna pada Lampu

\begin{tabular}{|c|c|c|}
\hline Lampu & $\begin{array}{c}\text { Temperatur } \\
\text { Warna (K) }\end{array}$ & Ra \\
\hline Fluoresen Standar & & \\
\hline White & 4200 & 60 \\
\hline Cool daylight & 6200 & 70 \\
\hline Fluoresen Super & & \\
\hline Warm white & 3500 & 85 \\
\hline Cool white & 4000 & 85 \\
\hline Cool daylight & 6500 & 85 \\
\hline Merkuri tekanan tinggi & 4100 & 50 \\
\hline Natrium tekanan tinggi & 1950 & 25 \\
\hline Halida Metal & 4300 & 65 \\
\hline
\end{tabular}

Sumber: Penulis (2018)

\section{B. Studi Aktifitas}

Pada area selasar terdapat tiga aktifitas utama yang dilakukan oleh mahasiswa yang meliputi pameran karya, kegiatan diskusi dan bisnis (working space). Menurut Timur Leorensi (2010:22) pameran adalah semua kegiatan yang dimaksudkan untuk menyampaikan atau mengkomunikasikan suatu produk kepada pasar sasaran, untuk memberi informasi tentang keistimewaan, kegunaan dan mengubah sikap siapapun untuk mendorong orang agar membelinya. Pameran dapat dibedakan menjadi tiga jenis, yaitu pameran tetap, temporer dan keliling. Aktifitas selanjutnya, working space merupakan sebuah area bagi sekumpulan orang 
Caesario A. Budianto, R. Adi Wardoyo, Thomas A. Kristianto, Anggra A. Rucitra, Okta P. S. Ardianto Studi Sistem Pencahayaan Buatan Adaptif untuk Selasar Aktivitas Gedung Baru Departemen Desain Interior ITS

yang bekerja secara independen. Desain meja kerja ditata menyerupai meja kerja pada umumnya beserta lampu, kursi dan stop kontak yang memadai. Setiap ruang kerja diatur sedemikian rupa, sehingga tiap orang yang bekerja dalam ruangan mendapat udara sedikitnya 10-15 m3. Luas tempat kerja staf paling sedikit 2,2 $\mathrm{m}^{2}$, merujuk pada Pedoman Teknis Pembangunan Bangunan Gedung Negara. Peralatan kerja mengacu pada antropometri, dengan tinggi meja berkisar 73,7 - 76,2 cm, lebar area kerja ideal 76,2 - 91,4 cm dan panjang meja $152,4-182,9 \mathrm{~cm}$.

\section{Simulasi dan Analisa}

Berdasarkan hasil simulasi sistem pencahayaan selasar aktivitas lantai satu dan lantai tiga gedung baru desain interior ITS, rata-rata tingkat pencahayaan selasar lantai satu lebih tinggi dibandingkan selasar lantai tiga. Perbedaan tersebut disebabkan karena selasar lantai satu memiliki tiga pintu masuk dari arah barat dan timur sehingga cahaya matahari langsung menuju selasar sedangkan di lantai tiga akses hanya melalui tangga. Rata-rata tingkat pencahayaan tertinggi pada kedua selasar jatuh pada tanggal 22 Juni 2018 dimana matahari berada di garis $23,5^{\circ}$ lintang utara dan mengalami musim kemarau. Pada pukul 18.00 WIB di semua tanggal, kedua selasar memiliki tingkat pencahayaan yang konstan dengan rata-rata kurang lebih 310 lux. Hal ini membuktikan kedua selasar sepenuhnya memanfaatkan pencahayaan buatan karena tidak ada cahaya matahari langsung.

Tabel 6. Hasil Simulasi Area Selasar Lantai 1

\begin{tabular}{|c|c|c|c|c|c|}
\hline \multirow{2}{*}{ NO } & \multirow{2}{*}{ TANGGAL } & \multirow{2}{*}{ PUKUL (WIB) } & \multicolumn{3}{|c|}{ TINGKAT PENCAHAYAAN ADAPTIF (lux) } \\
\hline & & & RATA-RATA & MINIMAL & MAKSIMAL \\
\hline 1 & 21 MARET 2018 & $8: 00$ & 3.513 & 83 & 29.724 \\
\hline 2 & 21 MARET 2018 & $12: 00$ & 1.323 & 72,5 & 37.731 \\
\hline 3 & 21 MARET 2018 & 18:00 & 311 & 19,7 & 2.156 \\
\hline 4 & 22 JUNI 2018 & $8: 00$ & 2.870 & 62,5 & 24.304 \\
\hline 5 & 22 JUNI 2018 & $12: 00$ & 2.635 & 124 & 41.236 \\
\hline 6 & 22 JUNI 2018 & $18: 00$ & 311 & 19,7 & 2.156 \\
\hline 7 & 22 DESEMBER 2018 & 8:00 & 3.627 & 143 & 32.196 \\
\hline 8 & 22 DESEMBER 2018 & $12: 00$ & 1.827 & 153 & 44.893 \\
\hline 9 & 22 DESEMBER 2018 & $18: 00$ & 311 & 19,7 & 2.156 \\
\hline \multicolumn{3}{|c|}{ TOTAL } & 1.859 & 77,5 & 24.061 \\
\hline
\end{tabular}

Sumber: Penulis (2018)

Tabel 7. Hasil Simulasi Area Selasar Lantai 3

\begin{tabular}{|c|c|c|c|c|c|}
\hline \multirow{2}{*}{ NO } & \multirow{2}{*}{ TANGGAL } & \multirow{2}{*}{ PUKUL (WIB) } & \multicolumn{3}{|c|}{ TINGKAT PENCAHAYAAN ADAPTIF (lux) } \\
\hline & & & RATA-RATA & MINIMAL & MAKSIMAL \\
\hline 1 & 21 MARET 2018 & $8: 00$ & 717 & 16,8 & 9.390 \\
\hline 2 & 21 MARET 2018 & $12: 00$ & 763 & 3,44 & 41.972 \\
\hline 3 & 21 MARET 2018 & 18:00 & 316 & 2,32 & 2.226 \\
\hline 4 & 22 JUNI 2018 & $8: 00$ & 705 & 14 & 14.385 \\
\hline 5 & 22 JUNI 2018 & $12: 00$ & 1.323 & 72,5 & 37.731 \\
\hline 6 & 22 JUNI 2018 & $18: 00$ & 316 & 2,32 & 2.226 \\
\hline 7 & 22 DESEMBER 2018 & $8: 00$ & 1.025 & 15,5 & 32.622 \\
\hline 8 & 22 DESEMBER 2018 & $12: 00$ & 1.284 & 14,4 & 43.483 \\
\hline 9 & 22 DESEMBER 2018 & $18: 00$ & 316 & 2,32 & 2.226 \\
\hline \multicolumn{3}{|c|}{ TOTAL } & 752 & 16,0 & 20.696 \\
\hline
\end{tabular}

Sumber: Penulis (2018) 
Range tingkat pencahayaan 1000-2000 lux merupakan rekomendasi nilai terhadap pekerjaan yang membutuhkan ketelitian tinggi sehingga rata-rata tingkat pencahayaan pada selasar lantai satu masih terbilang aman. Rata-rata tingkat pencahayaan minimal yaitu 77,5 lux yang juga terbilang aman karena standar minimal untuk area sirkulasi dalam ruang adalah 50 lux. Untuk rata-rata tingkat pencahayaan maksimal hingga 24.061 menandakan adanya areaarea yang menyilaukan sehingga kurang sesuai untuk melakukan aktivitas seperti pameran dan proses pembelajaran di area tersebut, maka dibutuhkan shading device atau vegetasi yang dapat mengurangi titik silau.

Tingkat pencahayaan 750 lux merupakan rekomendasi nilai terhadap pekerjaan yang membutuhkan ketelitian seperti pembacaan untuk koreksi tulisan sehingga sesuai dengan aktivitas co-working dan business startup. Rata-rata tingkat pencahayaan minimal yaitu 16 lux tergolong rendah dan belum memenuhi standar bahkan untuk humanisasi minimum. Untuk rata-rata tingkat pencahayaan maksimal hingga 20.696 lux menandakan adanya area-area yang menyilaukan sehingga perlu penanganan yang sama seperti pada area selasar lantai satu.

\section{Area Selasar Lantai 1}

Tabel 8. Perbandingan Hasil Simulasi Pencahayaan di Area Selasar Lantai 1 pada Tanggal 22 Juni

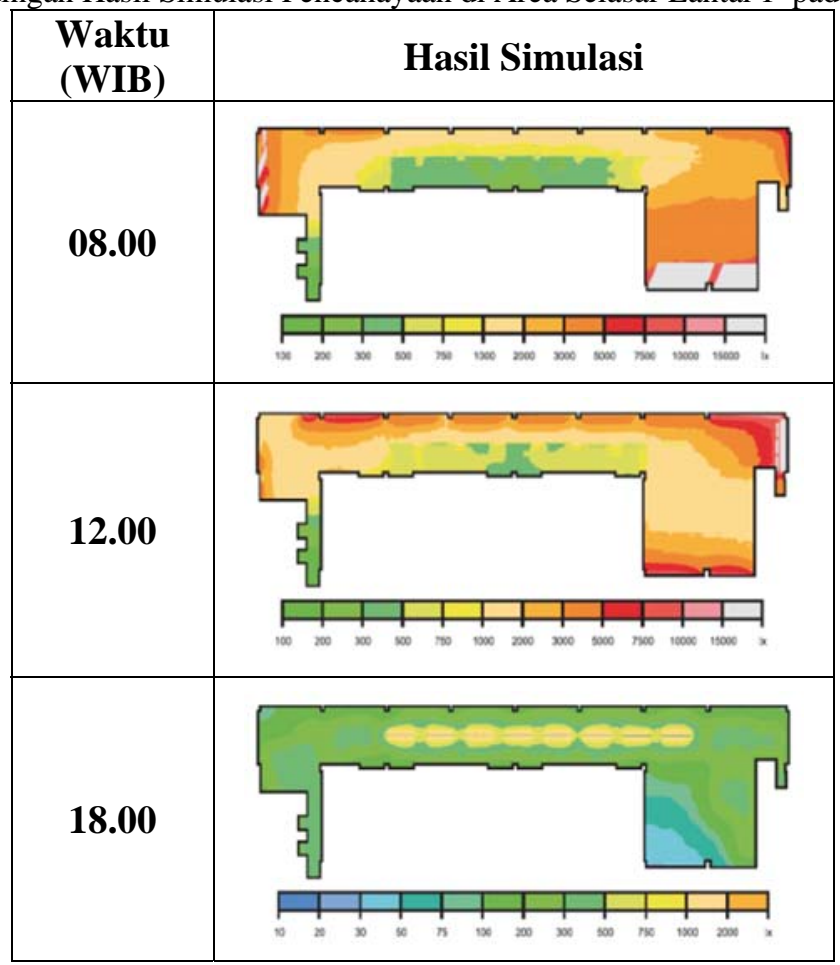

Sumber: Penulis (2018)

Tabel di atas menunjukkan perbedaan tingkat pencahayaan pada waktu yang berbeda di tanggal yang sama di selasar lantai satu. Warna biru tosca, biru, dan ungu bernilai dibawah 100 lux. Warna hijau memiliki tingkat pencahayaan berkisar 100-500 lux. Warna kuning dan oranye kekuningan berkisar 750-2000 lux. Warna oranye dan merah berkisar 3000-10000 lux. Warna merah muda dan abu-abu bernilai di atas 10000 lux. Pada pukul 08.00 WIB terdapat area silau di entrance bagian timur karena posisi matahari yang terbit dari timur. Pada pukul 12.00 WIB 
Caesario A. Budianto, R. Adi Wardoyo, Thomas A. Kristianto, Anggra A. Rucitra, Okta P. S. Ardianto Studi Sistem Pencahayaan Buatan Adaptif untuk Selasar Aktivitas Gedung Baru Departemen Desain Interior ITS

posisi matahari semakin tinggi sehingga sinarnya menjangkau bagian barat selasar yang memiliki banyak bukaan dan titik silau yang pagi hari berada di bagian timur berpindah ke bagian barat.

Area pameran yang berada di tengah selasar memiliki perbedaan tingkat pencahayaan pada pagi, siang, dan malam hari. Pada pagi hari area pameran dominan berkisar 300-500 lux. Pada siang hari dominan 500-750 lux. Pada malam hari dominan 750-2000 lux. Standard ideal ruang pamer adalah 300-500 lux [5]. Sehingga dapat disimpulkan aktivitas pameran dengan pencahayaan optimal pada pagi hari. Aktivitas yang membutuhkan pengerjaan berketelitian tinggi dapat dilaksanakan pada siang hari di selasar lantai satu karena tingkat pencahayaannya berkisar 1000-2000 lux namun tidak dianjurkan pada area sekitar pintu masuk dan bukaan baik di bagian utara, barat, dan timur. Untuk mengurangi tingkat pencahayaan di area entrance, dapat menggunakan vegetasi maupun shading advice.

\section{Area Selasar Lantai 3}

Tabel 9. Perbandingan Hasil Simulasi Pencahayaan di Area Selasar Lantai 3 pada Tanggal 22 Juni

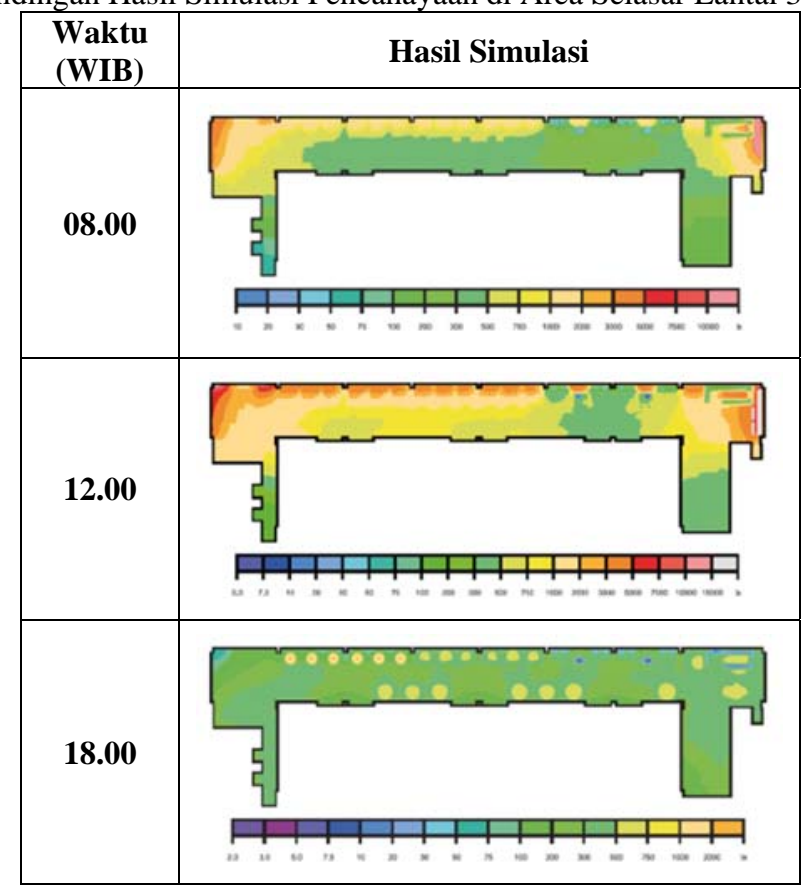

Sumber: Penulis (2018)

Tabel di atas menunjukkan perbedaan tingkat pencahayaan pada waktu yang berbeda di tanggal yang sama di selasar lantai tiga. Berbeda dengan lantai satu, titik silau pada lantai tiga tidak terlihat secara signifikan. Penyebabnya adalah cahaya matahari langsung tidak dapat menembus area selasar lantai tiga karena tidak ada celah berupa entrance seperti di lantai satu. Meskipun terdapat bukaan di sisi barat, kisi-kisinya dapat mengurangi cahaya matahari yang menuju area selasar. Hal ini dapat terlihat saat pukul 12.00 WIB cahaya dominan masih berkisar 500-1000 lux. Pada pukul 08.00 WIB warna dominan hijau menunjukkan tingkat pencahayaan berkisar 100-500 lux. Namun terdapat sedikit titik silau di bagian utara yang semakin terlihat hingga siang hari. Bagian utara yang merupakan pantry memiliki pencahayaan yang kurang baik saat pagi dan siang hari sehingga perlu adaya penambahan shading device. Area coworking berupa bilik dan startup bisnis juga memiliki pencahayaan yang kurang baik pada siang hari 
karena tingkat cahaya yang lebih dari 2000 lux ditunjukkan dengan warna oranye di sisi barat selasar.

Area kolaborasi industri memiliki tingkat pencahayaan konstan dari pagi hingga malam dengan dominan warna hijau berkisar 200-300 lux. Dalam hal display, pencahayaan ideal adalah 300 lux hingga 500 lux sehingga area kolaborasi industri masih belum memiliki pencahayaan optimal. Hal ini bisa disebabkan karena peletakan lampu saat proses simulasi baik dari segi arah pendaran cahaya atau ketinggian sumber cahaya yang belum bisa menjangkau permukaan bidang kerja berupa display.

Area co-working dan business startup memiliki pencahayaan paling optimal pada pagi dan malam hari. Tampak warna hijau dan kuning yang dominan merepresentasikan kisaran tingkat pencahayaan 300-1000 lux. Standar ideal ruang kerja mulai dari dari ketelitian rendah hingga ketelitian tinggi adalah 300-2000 lux.

\section{KESIMPULAN}

Berdasarkan penelitian yang telah dilakukan, didapatkan kesimpulan dengan poin-poin sebagai berikut.

1. Fasilitas untuk memenuhi kebutuhan mahasiswa di lantai satu terdiri dari pameran temporer dan proses pembelajaran. Waktu pameran yang kondisional menuntut pencahayaan buatan tambahan di samping general lighting yaitu accent lighting berupa tracklight sehingga dapat memenuhi standar pencahayaan area pamer yang berkisar 300500 lux.

2. Fasilitas untuk memenuhi kebutuhan mahasiswa di lantai tiga terdiri dari area co-working, business startup, kolaborasi industri dan pantry. Aktivitas mahasiswa baik akademik maupun non akademik membutuhkan fasilitas dengan pencahayaan sewaktu-waktu, sehingga dibutuhkan pencahayaan buatan. Pencahayaan buatan berupa general lighting dan task lighting karena jenis aktivitas pada selasar lantai tiga cenderung beragam. Pemilihan jenis lampu dan spesifikasinya dapat memenuhi standar pencahayaan optimal pada masingmasing aktivitas dengan kisaran 350-2000 lux untuk mengerjakan tugas, 300-500 lux untuk display produk, 125-250 untuk beristirahat.

3. Perlu adanya shading device yang optimal untuk menghindari titik silau pada suatu area yang memiliki aktivitas khusus padat saat memanfaatkan pencahayaan alami.

Penelitian yang telah dilakukan juga menghasilkan beberapa saran yang perlu diperhatikan dalam menentukan jenis pencahayaan buatan pada area selasar, antara lain:

1. Pentingnya memperhatikan tata cara perancangan sistem pencahayaan buatan oleh Badan Standardisasi nasional agar diperoleh jenis pencahayaan yang optimal untuk menunjang kegiatan yang dilakukan.

2. Perlu adanya data yang valid tentang kebutuhan pengguna area selaar untuk menentukan fasilitas, jenis furnitur dan pencahayaan yang dibutuhkan agar area selasar dapat dimanfaatkan dengan baik.

\section{DAFTAR PUSTAKA}

Akmal, Imelda. (2011). 32 Tata Cahaya untuk Rumah Tinggal. Jakarta: PT. Gramedia Pustaka Utama.

Kanisius. (2000). Pengelolaan Rumah Walet. Yogyakarta: Penerbit Kanisius.

Keputusan Menteri Kesehatan Republik Indonesia Nomor 1405/MENKES/SK/XI/2002 Tentang Persyaratan Kesehatan Lingkungan Kerja Perkantoran dan Industri 
Caesario A. Budianto, R. Adi Wardoyo, Thomas A. Kristianto, Anggra A. Rucitra, Okta P. S. Ardianto Studi Sistem Pencahayaan Buatan Adaptif untuk Selasar Aktivitas Gedung Baru Departemen Desain Interior ITS

Neufert, Ernst. (2002). Data Arsitek Edisi Jilid 1. Jakarta: Erlangga.

Tata Cara Perancangan Sistem Pencahayaan Buatan Pada Bangunan Gedung, SNI 03-65752001, 2001. Jakarta: Badan Standardisasi Nasional (BSN). 